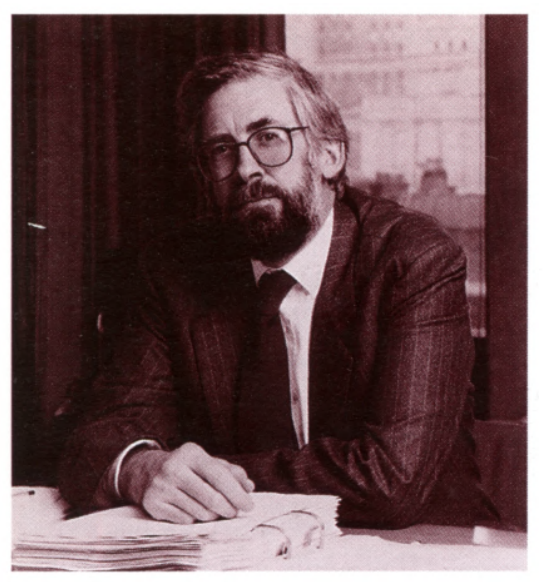

The School of Advanced Study is a federation of nine research institutes, and two programmes, involved with humanities and social sciences within the University of London. Founded in August 1994, the School assists the institutes to operate in an effective way: as Dean, Professor Daintith is equally concerned with academic and administrative initiatives in

Projects initiated by the School include new programmes like that in Philosophy; improving access to Institutes' specialist libraries through a common electronic catalogue; a computing network supporting the needs of individual institutes along with common ventures put in place by the School; and the development and use of fellowships. The system of fellowships operates both ąt Institute level, with externally-funded programmes such as the Frances Yates Fellowship at the Warburg Institute and the Nuffield Commonwealth Research and Training Fellowships at the Institute of Advanced Legal Studies making a major contribution, and within the central School fellowships programme where in 1996-97 ten visiting fellows were in residence.

Professor Daintith sees the area of fellowships as being particularly important.

'If you look at the institutes which make up the school, the factor they all have in common is their role as a national centre for research. We can make effective use of this to promote fellowships which will enlarge the

\title{
Professor Terence
}

\section{Daintith}

\author{
Professor Terence Daintith is Dean of the School \\ of Advanced Study within the University of \\ London He served as Director of the IALS from \\ 1988 to 1995 . He explains the role of the School, \\ and how he is developing it.
} areas where collaboration is desirable.

opportunities that individual scholars in other places have to come to London to use the libraries of the school, and also to use other conveniently-placed libraries nearby.

People can also participate in the collegiate life of each institute by attending seminars and lectures, giving and receiving criticism and so on. It is relatively easy for someone to attend a single lecture or series of lectures, but you also need to be able to accommodate people for longer periods within programmes which give some type of support. The institutes offer a mixture of fellowships, some carrying a stipend and others being non-stipendiary.

I would like to see the range of stipendiary fellowships extended, which is something the School wants to do collectively. We are also conscious of the fact that non-stipendiary fellowships properly administered within very high quality environments create a very powerful lever for individuals to get the funding that they require'.

The School is putting considerable effort into attracting external funding. Which objectives should be tackled collectively, and which by individual Institutes, needs careful consideration, but Professor Daintith feels that there are opportunities to be found across a wide area of the humanities and social sciences. As far as state funding is concerned, one advantage of the School in the current political climate is that the government or the higher education funding council would find it difficult to 'pick off' any one institute on the basis that it is less interesting than the others. By giving support and leadership, the

\section{CURRICULUM VITAE}

Born in 1942, Professor Terence Daintith taught at the Universities of California (Berkeley), Edinburgh and Dundee, and at the European University Institute in Florence, before coming to London in 1988 as Director of the Institute of Advanced Legal Studies. He works in the fields of constitutional law, law and economics, and energy law, and is currently (with Alan Page) writing a book on the executive in UK constitutional law.
School provides unity and an orderly pattern of activity in research which benefits and strengthens everybody.

It is not always easy for the School of Advanced Study to find very similar organisations in other countries with which to co-operate, although bodies with terms such as 'advanced study' or 'institute' in their title are relatively common. Professor Daintith feels that more could be done to develop links with appropriate organisations, although it is important to establish particular objectives and your own position in relation to public funding.

The School of Advanced Study does not number a science institute among its member organisations, but Professor Daintith is aware of the need not to be completely cut off from science.

'We have begun to make moves in this direction by running a number of lectures, including the Coffin Lecture which takes in various subjects, one of which has traditionally been science. One lecture dealt with the philosophy of science, and we have a number of possible angles of approach which could be productive if pursued'.

\section{SCHOOL OF ADVANCED STUDY}

The School is composed of the following member institutes: Institute of Advanced Legal Studies; Institute of Classical Studies; Institute of Commonwealth Studies; and Sir Robert Menzies Centre for Australian Studies; Institute of Germanic Studies; Institute of Historical Research; Institute of Latin American Studies; Institute of Romance Studies; Institute of US Studies; Warburg Institute; and has initiated two programmes centrally - Centre for English Studies; Philosophy Programme. 